\title{
The Efficacy of Antioxidant (Vitamin C) in the Treatment and Management of Malaria
}

Mgbemena*, Ifeyinwa Celestina

Department of Biotechnology, Federal University of Technology, P. M. B. 1526, Owerri, Imo State, Nigeria

DOI: $10.36347 /$ sajp.2020.v09i04.003

| Received: 19.03.2020 | Accepted: 26.03.2020 | Published: 30.04 .2020

*Corresponding author: Mgbemena

Abstract

Original Research Article

The study examines the effects of Vitamin $\mathrm{C}$ on malaria parasitamae and the biochemical parameters which is an indicative of the liver function. Twenty wistar Albino rats were by average weight of $100-250 \mathrm{~g}$ divided into 5 groups, Groups 1) served as normal control(NC), group 2 as experimental groups (PC), (Group 3 \& 4 ) served as Vitamin $\mathrm{C}$ and group 5 served as Artesunate control. All the groups were inoculated with a chloroquine-sensitive strain of Plasmodium berghei NK-65 following the administration of vitamin $\mathrm{C}$ and artesunate drugs. The Animals were treated for 4 days after 24 hours, post infection with $P$. berghei. Parasitemia levels were assessed by examining Giemsa-stained thin blood smears from each animal via an optical microscope on days 4 and 7 . Blood samples collected from the animals via cardiac puncture with the aid of a capillary tube, was allowed to clot for 45 min at room temperature. Serum was separated by centrifugation at 6,000rpm for $15 \mathrm{~min}$ and analyzed for liver function parameters. There was a significant suppression $(\mathrm{P}<0.05)$ in total parasite count $(205.00 \& 137.00$ and $242.25 \&$ 157.00) on days 4 and 7 when compared with the other controls (300.75 \& 403.25), as well as a reduction in liver function parameters with Vitamin $\mathrm{C}$ at $15 \mathrm{mg} \& 7.5 \mathrm{mg}$. This study however shows that vitamin $\mathrm{C}$ administration to $P$. berghei infected rats resulted in reducing parasite count as well as reduced malaria related alteration of liver function markers.

Keywords: Vitamin C, Plasmodium berghei, Malaria, Parasitemia, Antioxidant.

Copyright @ 2020: This is an open-access article distributed under the terms of the Creative Commons Attribution license which permits unrestricted use, distribution, and reproduction in any medium for non-commercial use (NonCommercial, or CC-BY-NC) provided the original author and source are credited.

\section{INTRODUCTION}

Malaria is a mosquito-borne infectious disease affecting humans and other animals caused by parasitic single-celled microorganisms belonging to the Plasmodium group [1]. The five important species of the parasite that cause this disease are; Plasmodium falciparum, P. malariae, P. knowlesi (this plasmodium causes malaria in long-tailed macaques [Macaca fascicularis] but it may also infect humans, either naturally or artificially), $P$. ovale and $P$. vivax. In Nigeria, human malaria is mostly caused by Plasmodium falciparum and Plasmodium malariae and transmitted by female anopheles mosquito. Malaria causes symptoms that typically include fever, tiredness, vomiting, and headaches, shivering, joint pain, vomiting, hemolytic anemia, jaundice, hemoglobin in the urine, retinal damage, and convulsions. In severe cases it can cause yellow skin, seizures, coma, or death [2].

The prevention of this fatal disease can possibly be achieved through the control of malaria vector and usage of antimalarial drugs. Vector control as the main way to prevent and reduce malaria transmission involves two control strategies insecticide-treated mosquito nets and indoor residual spraying are effective in a wide range of circumstances. Also, antimalarial drugs have come in handy in the fight against malaria. A couple of antimalarial drugs have been used in clearing parasitaemae and they include quinolones, antifolates, antibiotics, artemisinin and their derivatives.

Recent developments in biomedicals point to the involvement of free radicals in many diseases [3]. In spite of all the efforts geared in the fight against malaria, oxidative damage still remains one of the most important pathological consequences of malarial infections and recent reports suggest that generation of reactive oxygen species and associated oxidative stress play crucial role in the development of systemic complications in malaria [4]. It affects vital organs of the body manifesting in changes such as splenomegaly, hepatomegaly, endothelial and cognitive damages. Free 
radicals particularly reactive oxygen species have a greater impact on humans. Free radicals attack the unsaturated fatty acids in the biomembranes resulting in membrane fluidity. Antioxidants can greatly reduce the damage due to oxidants by neutralizing the free radicals before they attack the cells to prevent damages to the lipids, proteins, enzyme, carbohydrate and DNA. Antioxidants plays important role in inhibiting and scavenging free radicals, thus providing protection against infections and degenerative diseases. For these reasons antioxidants are of interest for the treatment of many kinds of cellular degeneration [3]. Some research investigations have focused attention on the use of antioxidants, alone or in combination with antimalarials, as a viable therapeutic strategy aimed at alleviating plasmodium-induced oxidative stress and its associated complications. The most frequently investigated antioxidants are vitamins $\mathrm{C}$ and $\mathrm{E}, \mathrm{N}$ acetylcystein, folate and desferroxamine [5]. This work is aimed at determining the antioxidant effects of Vitamin $\mathrm{C}$ on Albino rats infected with Plasmodium berghei.

\section{MATERIALS AND METHODS}

This practical work was carried out at Silver Presh Laboratories, No. 25 Mbaise Road, Owerri, Imo state.

\section{Experimental Animals}

Twenty (20) male wistar albino rats weighing $100-250 \mathrm{~g}$ were purchased from an animal breeding station, Animal friend farms, No. 92 Royce road Owerri, Imo State. The animals were maintained under standard laboratory condition in a stainless steel cages with free access to standard animal feed (Pelletised, Vital finisher) and portable drinking water Ad libitum. They were acclimatized for four days prior to use. The twenty wistar albino rats were divided into five groups of four animals each to serve for the in vivo suppressive test with Plasmodium berghei.

\section{Parasite, P. berghei (NK65)}

$P$. berghei parasite was obtained from the Department of Veterinary Medicine, University of Nigeria, Nsukka. The infected blood suspension containing $1 \times 10^{5} P$. berghei NK65 was transported in an ice-pack and used immediately for passaging on arrival. Each rat was inoculated intraperitoneally (IP), with a parasite load of $1 \times 10^{5}$ P. berghei NK65 pRBCs.

\section{In vivo Suppressive Test}

Evaluation of the in vivo antimalarial activity was performed based on the Peters 4-day suppressive test [6] with modifications [7]. Briefly, $0.2 \mathrm{ml}$ of infected blood suspension containing $1 \times 10^{5} \mathrm{P}$. berghei NK65 pRBCs was inoculated intraperitoneally in the rats. The animals were randomly divided into groups of four animals each as follows:
Group 1 or control group (NC) received normal rat diet and water orally for 7 days.

Group 2 or experimental group received $0.2 \mathrm{ml}$ of infected blood suspension containing $1 \times 10^{5} P$. berghei NK65 pRBCs by intraperitoneal route in a single dose, in addition to normal rat diet and water throughout the 7 days.

Group 3 or test group 1 was administered with $0.2 \mathrm{ml}$ of infected blood suspension containing $1 \times 10^{5} \mathrm{P}$. berghei NK65 pRBCs by intraperitoneal route in a single dose, $15 \mathrm{mg} / \mathrm{kg}$ body weight of the Vitamin $\mathrm{C}$ (1000mg, Nature Field U.S.A), (obtained from Sure Care Pharmacy LTD, Plot OB/5 Housing Area E, Opposite All Season Hotels, New Owerri, Imo State, Nigeria, for 7 days in addition to normal rat diet and water.

Group 4 or test group 2 received $0.2 \mathrm{ml}$ of infected blood suspension containing $1 \times 10^{5} \mathrm{P}$. berghei NK65 pRBCs administered intraperitoneally in a single dose, $7.5 \mathrm{mg} / \mathrm{kg}$ body weight of the Vitamin $\mathrm{C}$ for 7 days in addition to normal rat diet and water.

Group 5 or the standard group received $0.2 \mathrm{ml}$ of infected blood suspension containing $1 \times 10^{5} P$. berghei NK65 pRBCs which was also inoculated intraperitoneally in a single dose, $2.86 \mathrm{mg} / \mathrm{kg}$ body weight of the artesunate( Mekophar chemical pharmaceutical joint company, Vietnam), (obtained from Sure - Care Pharmacy LTD, Plot OB/5 Housing Area E, Opposite All Season Hotels, New Owerri, Imo State, Nigeria), for 7 days in addition to normal rat diet and water.

All the Animals were treated for 4 days after 24 hours, post infection with $P$. berghei. Parasitemia levels were assessed by examining Giemsa-stained thin blood smears from each animal via an optical microscope on days 4 and 7 . The difference between the average parasitemia of negative-control groups (100\%) and test groups was calculated as the percentage of parasite growth suppression (PGS) according to the following equation: $\mathrm{PGS}=100 \times[(\mathrm{A}-\mathrm{B}) / \mathrm{A}]$, Where, $\mathrm{A}$ is the average parasitemia of the negative-control group and B corresponds to the parasitemia of the test group. Each sample was tested in 3 independent experiments.

\section{Biochemical Assay}

After administration for 7 days, all the animals were fasted for 24 hours and sacrificed under light anesthesia. Blood samples was collected via cardiac puncture with the aid of a capillary tube and allowed to clot for $45 \mathrm{~min}$ at room temperature. Serum was separated by centrifugation at 6,000rpm for $15 \mathrm{~min}$ and analyzed for liver function parameters. 


\section{Assay of Serum Aspartate Aminotransferase (AST)} Activity

Determination of AST activity was based on the method of [8]. The spectrophotometer was set at wavelength of $546 \mathrm{~nm}$ and incubation temperature at $37^{\circ} \mathrm{C}$. Just like the procedure for the determination of ALT activity, this test is carried out in two steps.

\section{Step1 Measurement against reagent blank}

A pipette was used to measure appropriately, $0.1 \mathrm{ml}$ of serum, $0.5 \mathrm{ml}$ of buffer (phosphate buffer $100 \mathrm{mmol} / 1, \quad$ L-aspartate $100 \mathrm{mmol} / 1, \alpha$ - oxoglutarate $2 \mathrm{mmol} / \mathrm{l}$. These chemicals were mixed and incubated for exactly 30 minutes at $37^{0} \mathrm{C}$. $0.5 \mathrm{ml}$ of 2 , 4dinitrophenylhydrazine was added, mixed and allowed to stand for exactly $20 \mathrm{~min}$ at $20^{\circ} \mathrm{C}$. Finally, $5.0 \mathrm{ml}$ of sodium hydroxide was added, mixed and the absorbance of the sample read against the blank after five minutes.

\section{Step 2 Measurement against sample blank}

A pipette was used to appropriately measure $0.1 \mathrm{ml}$ of serum and buffer. They were mixed and incubated for exactly 30 minutes at $37^{0} \mathrm{C} .0 .5 \mathrm{ml}$ of 2,4 dinitrophenylhydrazine and an additional $0.1 \mathrm{ml}$ of serum were added, mixed and allowed to stand for exactly 20 minutes at $20^{\circ} \mathrm{C}$. Finally, $5 \mathrm{ml}$ of sodium hydroxide was added and the absorbance of the sample read against the sample blank after 5minutes. Activity of AST in the serum was obtained from the table below:

Determination of Alanine aminotranferases activity The spectrophotometer was set at wavelength $546 \mathrm{~nm}$ and incubation temperature at $37^{\circ} \mathrm{C}$. This test was carried out in two steps.

\section{Step 1 Measurement against reagent blank}

Serum was mixed appropriately with $0.5 \mathrm{ml}$ buffer and $0.1 \mathrm{ml}$ of distilled water. The mixture was incubated for exactly 30 minutes at $37^{\circ} \mathrm{C} .0 .5 \mathrm{ml}$ of 2,4 dinitrophenylhydrazine was added, mixed and allowed to stand for 20 minutes at $25^{\circ} \mathrm{C}$. Finally, $5 \mathrm{ml}$ of sodium hydroxide was added, mixed and the absorbance of the sample read against the reagent blank after 5 minutes.

\section{Step 2 Measurement against sample blank}

$0.1 \mathrm{ml}$ of serum was mixed with buffer and incubated for exactly 30 minutes at $37^{\circ} \mathrm{C}$. $0.5 \mathrm{ml}$ of 2, 4dinitrophenylhydrazine was added with an additional $0.1 \mathrm{ml}$ of serum. They were mixed and allowed to stand for exactly $20 \mathrm{~min}$ at $25^{\circ} \mathrm{C}$. Finally, sodium hydroxide was added and mixed. The absorbance of the sample was read against the sample blank after 5 minutes. The activity of alanine aminotransferases (ALT) was extrapolated from the table below;

Table-1: Determination of alanine aminotransferases activity

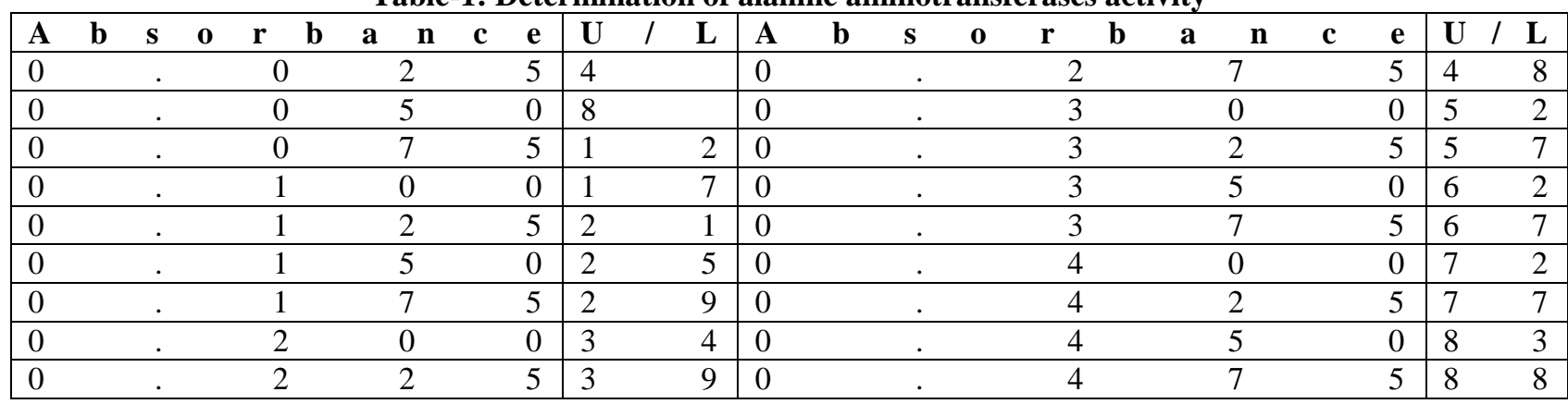

\section{Assay of Serum Alkaline Phosphatase (ALP) activity}

ALP activity was determined according to the method described by [9]. Procedure: The reagents were brought to room temperature, and reagents were pipetted into labeled cuvettes as follows: $1.0 \mathrm{ml}$ of the ALP reagent was pipetted into a cuvette serving as blank and sample cuvette. Into the blank, $0.02 \mathrm{ml}$ of distilled water was added and used to zero the spectrophotometer. Into another cuvette $1.0 \mathrm{ml}$ of ALP reagent was pipetted and $0.02 \mathrm{ml}$ of serum was added, mixed and initial absorbance read. The timer was started simultaneously and the absorbance read after 1 minute, 2 and 3 minutes interval respectively.

\section{The ALP activity was calculated as follows CALCULATIONS}

ALP activity $(\mathrm{U} / \mathrm{L})=(\Delta \mathrm{A} 405 \mathrm{~nm} / \mathrm{min}) \times 2760$

Where; $\Delta \mathrm{A}=$ Change in absorbance, $\min =$ minutes

\section{Estimation of Total bilubirin}

The method that exploits the use of diazotized sulphanilic acid as described by $(10,11]$ was used. Colorimetric method based on that described by [12] was used. Direct bilubirin reacts with diazotized sulphanilic acid in alkaline medium to form blue coloured complex. Total bilubirin is determined in the presence of caffeine, which releases albumin bond bilubirin, by the reaction with diazotized sulphanilic acid.

The colorimeter was set at wavelength of $578 \mathrm{~nm}$; temperature at $25^{\circ} \mathrm{C}$ and measurement was made against sample blank. 200ul sulphanilic acid, 500ul sodium nitrite and 1000ul caffeine were mixed with 200ul of serum and allowed to stand for 10minutes at $20^{\circ} \mathrm{C}$. Tartrate was added, mixed and allowed to stand for $5-30 \mathrm{~min}$ at $25^{\circ} \mathrm{C}$ and then the absorbance of the sample read against the sample blank. 
RESULTS

Parasite Count of Malaria Infested Rats Administered with Vitamin C

Result showed that administration of Vitamin

$\mathrm{C}$ had a suppressive effect on parasite count at day 4 and day 7. The parasite count were significantly $(\mathrm{P}<0.05)$ increased in $\mathrm{PC}$ groups compared to other groups. Administration of artesunate and Vitamin $\mathrm{C}$ at $15 \mathrm{mg} \& 7.5 \mathrm{mg}$ dosages produced significant suppression of parasite load in $P$. berghei infected rats.

Table-1: Parasite Count of Malaria Infested Rats Administered Vitamin C

\begin{tabular}{|l|l|l|l|l|l|}
\hline Days & NC & PC & $\begin{array}{l}\text { Vit.C15mg/Kg } \\
\text { bodyweight }\end{array}$ & $\begin{array}{l}\text { VitC7.5mg/Kg } \\
\text { bodyweight }\end{array}$ & $\begin{array}{l}\text { ART 2.86mg/Kg } \\
\text { bodyweight }\end{array}$ \\
\hline Day 4 & $0.0 \pm 0.0^{\mathrm{a}}$ & $300.75 \pm 35.39^{\mathrm{C}}$ & $205 \pm 46.01^{\mathrm{b}}$ & $242.25 \pm 48.24^{\mathrm{b}, \mathrm{c}}$ & $48.25 \pm 11.03^{\mathrm{a}}$ \\
\hline Day 7 & $0.0 \pm 0.0^{\mathrm{a}}$ & $403.25 \pm 53.06^{\mathrm{C}}$ & $137.00 \pm 20.05^{\mathrm{b}}$ & $157.00 \pm 60.52^{\mathrm{b}}$ & $0.00 \pm 0.00^{\mathrm{a}}$ \\
\hline
\end{tabular}

Counts are Mean \pm Standard deviation of 4 determinations

Mean with different superscript are significantly different $(\mathrm{P}<0.05)$

Effect of Vitamin C administration on serum Alanine Aminotransferase (ALT) activity on male wistar albino rats administered for 7 days

The result below (Figure 1) illustrates the effect of vitamin $\mathrm{C}$ on the liver ALT activity of treated albino rats with Plasmodium berghei. Results showed that ALT activity was significantly increased $(\mathrm{P}<0.05)$ in parasitemic control group. However administration of vitamin $\mathrm{C}$ at $7.5 \mathrm{mg} / \mathrm{kg}$ Body weight and $15 \mathrm{mg} / \mathrm{kg}$ body weight resulted in significant $(\mathrm{P}<0.05)$ reduction in ALT activity when compared to PC.

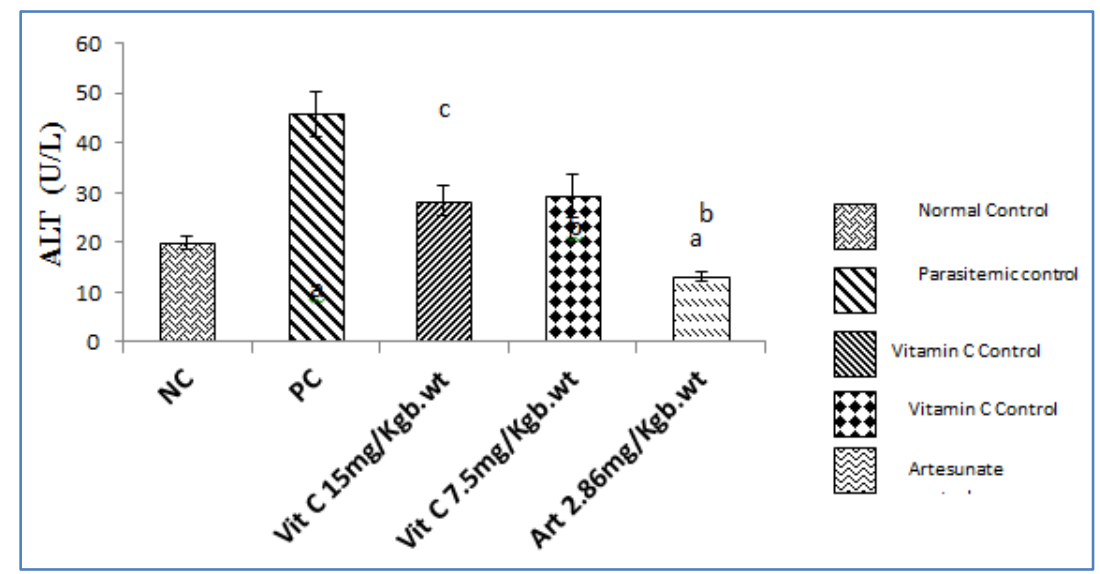

Fig-1: Effect of Vitamin C Administration on Serum Alanine Aminotransferase Activities on Malaria Infected Male Wistar Albino Rat

Results are mean \pm SD of 4 determinations and Mean values with different superscript are significantly different among groups at $(\mathrm{P}<0.05)$.

Effect of Vitamin C Administration on Serum Aspartate Aminotransferase (AST) Activity on Male Wistar Albino Rats Administered For 7 Days
Results (Figure 2) showed that AST activity was slightly increased in parasitemic control group and parasitemia induced groups. However, administration of vitamin $\mathrm{C}$ at $7.5 \mathrm{mg} / \mathrm{kg}$ body weight and $15 \mathrm{mg} / \mathrm{kg}$ body weight and Artesunate $2.86 \mathrm{mg} / \mathrm{kgb}$.wt did not significantly reduce AST activity when compared to PC and NC.

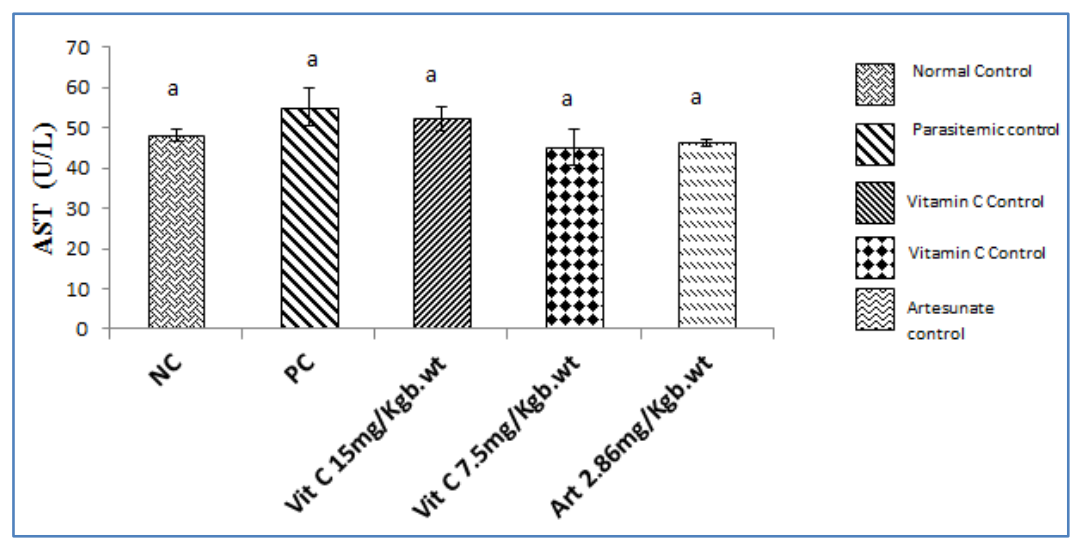

Fig-2: Effect of Vitamin C Administration on Serum Aspartate Aminotransferase Activities of Malaria Infected Male Wistar Albino Rat 
Results are mean \pm SD of 4 determinations and Mean values with different superscript are significantly different among groups at $(\mathrm{P}<0.05)$.

\section{Effect of Vitamin C Administration on Serum Alkaline Phosphatase (ALP) Activity on Male Wistar Albino Rats Administered For 7 Days}

The result below (Figure 3) illustrates the effect of vitamin $\mathrm{C}$ on the Liver ALP activity of infected albino rats with Plasmodium berghei. That ALP activity was increased in parasitemic control group, Vitamin C $15 \mathrm{mg} / \mathrm{kg}$ body weight, Vitamin C $7.5 \mathrm{mg} / \mathrm{kg}$ body weight, artesunate $2.86 \mathrm{mg} / \mathrm{kg}$ body weight compared to normal control. However, this increase were not significant $(\mathrm{P}<0.05)$.

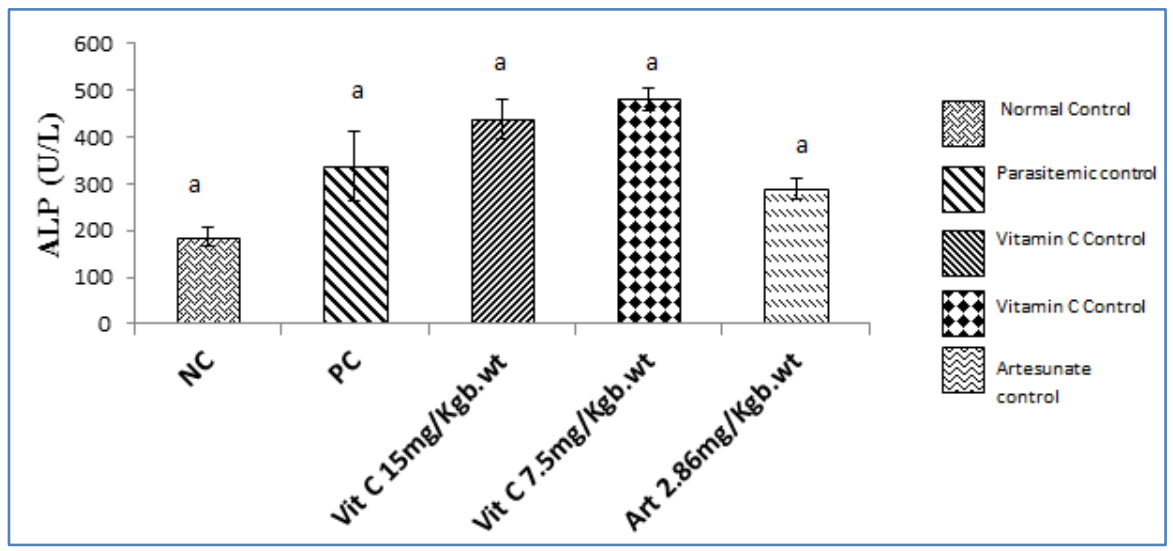

Fig-3: Effect of Vitamin C Administration on Serum Alkaline Phosphatase Activities on Malaria Infected Male Wistar Albino Rat

\section{Effect of Vitamin C Administration on Serum Total Bilirubin (T/Bil) Activity on Male Wistar Albino Rats Administered for 7 Days}

Result obtained from this study (figure 4) showed that the effect of vitamin $\mathrm{C}$ on the total bilirubin concentration of albino rats infected with Plasmodium berghei. That total bilirubin activity was significantly increased $(\mathrm{P}<0.05)$ in parasitemic control group but administration of vitamin $\mathrm{C}$ at both $7.5 \mathrm{mg} / \mathrm{kg}$ body weight and $15 \mathrm{mg} / \mathrm{kg}$ body weight resulted in significant reduction in total bilirubin activity when compared to PC.

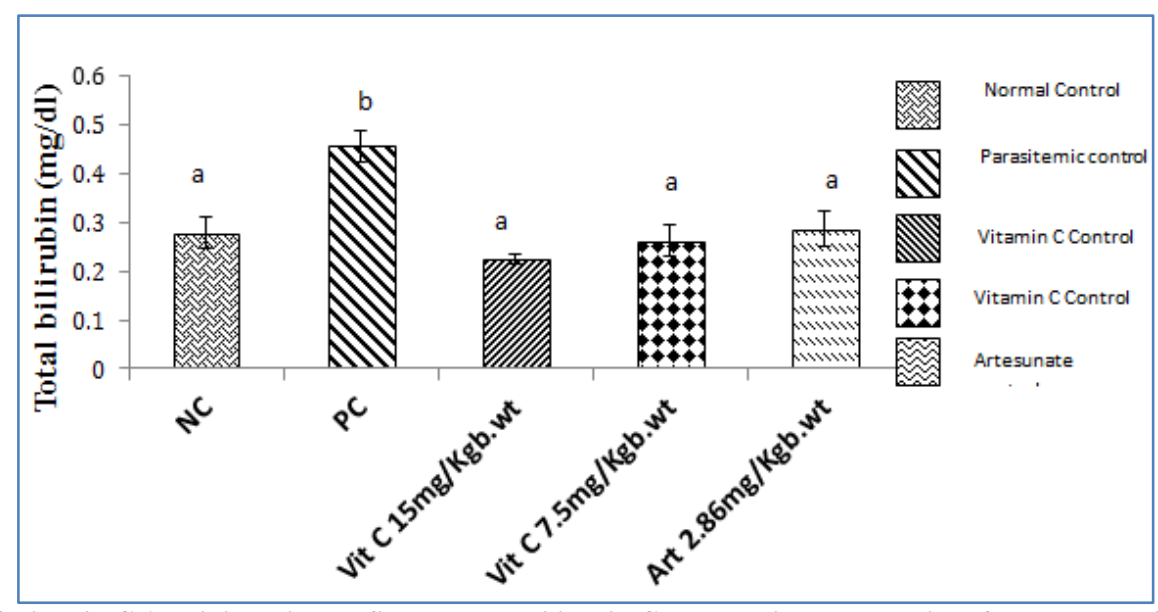

Fig-4: Effect of Vitamin C Administration on Serum Total Bilirubin Concentration on Malaria Infected Male Wistar Albino Rat

Results are mean \pm SD of 4determinations and Mean values with different superscript are significantly different among groups at $(\mathrm{P}<0.05)$.

\section{DISCUSSION}

Treatment of malaria can be affected by the use of a variety of antimalarial drugs which are readily available and can be purchased over the counter. ACTs are currently relied upon as first-line therapy for effective malaria treatment in most regions of the world in which the disease is endemic since they are effective, less toxic and well tolerated [13, 14] and their continuing efficacy is crucial if control and elimination programs are to succeed. The loss of effectiveness of artemisinin and its derivatives to drug resistance constitutes a major disaster in the fight against malaria.

This work studied the efficacy of Vitamin C in the treatment of malaria and its protective activity on the liver of rat infected with plasmodium berghei. Vitamin C (Ascorbic Acid) is a water soluble vitamin that acts as an antioxidant, especially protecting the immune system cells from free radicals generated during their assault on invaders [15]. It has, therefore 
been suggested that vitamin $\mathrm{C}$ supplementation may have a role in case management of malaria [16]. Indeed, the plasma concentration of this antioxidant has been reported to be significantly decreased in chronic and acute malaria infections $[17,18]$.

However, analysis of malaria parasite count showed that administration of vitamin $\mathrm{C}$ to malaria infested rat significantly suppressed parasite count. Result obtained (Table 1) showed that parasite count in groups treated with vitamin $\mathrm{C} 7.5 \mathrm{mg} / \mathrm{kg}$ and $15 \mathrm{mg} / \mathrm{Kg}$ body weight caused significant reduction in parasite count when compared to the parasite control group. Vitamin $\mathrm{C}$ had a suppressive effect on parasite count after four and seven day administration. Furthermore, the results showed that liver function indices (ALT, ALP) activities were significantly increased $(\mathrm{P}<0.05)$ by $P$. berghei infestation as well as total bilirubin concentration. However, the treatment of infested rats with artesunate and vitamin $C$ significantly $(p<0.05)$ reduced liver function enzymes activity and total bilirubin concentration. However, AST activity was not significantly altered across the groups. The liver is a primary site for xenobiotics detoxification, its metabolism is readily altered by toxicity as well as malaria parasitemia. Liver transaminases (ALT, AST) activity, alkaline phosphatases, total bilirubin are employed as indicators of hepatocellular damage. Damage to the liver results in increase in their activities in the plasma, increase in their activites is roughly to the extent of tissue damage [19]. Administration of vitamin $\mathrm{C}$ reduced alteration of liver function in malaria parasitemia.

Hyperbilirubinaemia is characteristic of impaired bilirubin metabolism involving metabolic disturbances in the liver resulting to defective conjugation, transport and, or excretion of bilirubin or overproduction of bilirubin caused by an excessive breakdown of red cells which may be due to severe falciparum malaria, sickle cell disease, haemolysis associated with glucose-6-phosphate dehydrogenase deficiency and toxins from bacteria, snake venoms, drugs or herbs etc. The measurement of serum bilirubin is performed to investigate the causes of liver disease and jaundice. In the present study, vitamin C administration resulted in normalization of bilirubin concentration.

\section{CONCLUSION}

The present sudy investigated the use of antioxidant vitamin $\mathrm{C}$ in the treatment and management of malaria. The findings showed that vitamin $\mathrm{C}$ administration to $P$. berghei infected rats resulted in a significant suppression of parasitemia as well as reduced malaria related alteration of liver function markers.

\section{ACKNOWLEDGEMENT}

The author wishes to express her deep and heartfelt gratitude to the staff and management of Silver Presh laboratories, No. 25 Mbaise Road, Owerri, Imo state for their immense contribution in the analysis of samples.

\section{CONFLICT OF INTEREST}

The author declares no conflict of interests of any kind.

\section{REFERENCES}

1. Mueller I, Zimmerman PA and Reeder JC. Plasmodium malariae and Plasmodium ovale the 'bashful' malaria parasites.2007; 23(6: 278 - 283.)

2. Beare NA, Taylor TE, Hardin SP, Lawallen, S. and Molyneux ME. "Malarial Retinopathy: A newly established diagnostic sign in severe malaria". American Journal of Tropical Medicine and Hygiene. 2006; 75(5):790-7.

3. Behera BC, Verma N, Sonone A and Makhija U. Determination of antioxidant potential of Lichen Usnea ghattensis in vitro LWT.2006; 39: 80 - 85.

4. Pabon A, Carmona J, Burgos LC and Blair S. Oxidative stress in patients with non - complicated malaria. Clinical Biochemistry.2003; 36: 71 -78.

5. Isah MB and Ibrahim MA. The role of antioxidants treatment on the pathogenesis. Parasitology Research.2014; 113(3):801-9.

6. Peter W, Portus $\mathrm{H}$ and Robinson L. The four-day suppressive in vivo antimalarial test. Ann Trop Med Parasitol. 1995; 69:155-171.

7. Rocha eSilva LF, Pinto ACS, Pohlit AM, Quignard ELJ, Vieira PPR, Tadei WP, Chaves FCM, Samonek JF, Lima CA, Costa MR, Alecrim MG, Andrade-Neto VF. In vivo and in vitro antimalarial activity of 4-nerolidylcatechol. Phytother Res.2011; 25:1181-1188.

8. Reitman S and Frankel S. A colorimetric method for the determination of serum oxaloacetatic and glutamic pyruvic transaminases. American Journal of Clinical Pathology.1995; 28.

9. Englehardt A. Measurement of alkaline phosphatase. Aerztl Labor.1970; 16:42.

10. Pearlman FC and Lee RT. Detection and measurement of total bilirubin in serum, with use of surfactants as solubilizing agents. Clinical chemistry. 1974; 20:447-453.

11. Zoppi FP A, Felini D, Marcovina S and Ramella C. Metodo per la determinazione della bilirubin totale e conlugata. Uso di un tensioaltivo cationico come agentte solubilizzantte. Giorn ital chim clinica. 1976; 1:343-359.

12. Jendrassik L and P Grof. Estimation of total serum bilirubin level by spectrophotometrically in serum and plasma. Biochemische Zeitschrift.1938; 297: 81-89.

13. Nanyunja M, Nabyonga Orem J, Kato F, Kaggwa M, Katureebe C, Saweka J. Malaria treatment policy change and implementation: the case of 
Uganda. Malaria research and treatment. 2011;2011.

14. Cui L, Su XZ. Discovery, mechanisms of action and combination therapy of artemisinin. Expert review of anti-infective therapy. 2009 Oct 1;7(8):999-1013.

15. Wintergerst ES, Maggini S, Hornig DH. Immuneenhancing role of vitamin $\mathrm{C}$ and zinc and effect on clinical conditions. Annals of Nutrition and Metabolism. 2006;50(2):85-94.

16. Marva E, Golenser J, Cohen A, Kitrossky N, HarEl R, Chevion M. The effects of ascorbate-induced free radicals on Plasmodium falciparum. Tropical medicine and parasitology: official organ of
Deutsche Tropenmedizinische Gesellschaft and of Deutsche Gesellschaft fur Technische Zusammenarbeit (GTZ). 1992 Mar;43(1):17-23.

17. Mohammad A. Effect of serum antioxidant ascorbic acid concentration by malarial infection. Man. The Experiment.2012; 3(4): 214215.

18. D'souza V, D'souza B. Comparative study on lipid peroxidation and antioxidant vitamins $\mathrm{E}$ and $\mathrm{C}$ inFalciparum andVivax malaria. Indian Journal of Clinical Biochemistry. 2006 Sep 1;21(2):103-6.

19. Gaw A, Cowman RA, O'Reilly DS and Shepherd J. Clinical Biochemistry: An Illustration color Text. Clinical Biochemistry, New York; 1995. 